\title{
FERTILIZAÇÃO DE LIBERAÇÃO CONTROLADA NO CRESCIMENTO INICIAL DE ANGICO-BRANCO ${ }^{1}$
}

\section{CONTROLLED-RELEASE FERTILIZATION ON THE ANGICO-BRANCO INITIAL GROWTH}

\author{
Gilvano Ebling BRONDANI² \\ Ariadne Josiane Castoldi SILVA ${ }^{3}$ \\ Suelen Santos REGO 4 \\ Fernanda Almeida GRISI ${ }^{5}$ \\ Antonio Carlos NOGUEIRA ${ }^{6}$ \\ Ivar WENDLING ${ }^{7}$ \\ Marla Alessandra de ARAUJO ${ }^{8}$
}

\begin{abstract}
RESUMO
O uso de fertilizantes de liberação controlada constitui-se em uma das modernas técnicas na produção de mudas. Porém, existem poucos relatos de seus efeitos sobre o crescimento em espécies florestais nativas. Objetivou-se testar doses crescentes de fertilizante de liberação controlada no crescimento inicial de mudas de angico-branco. As mudas foram originadas de sementes, semeadas em tubetes $\left(110 \mathrm{~cm}^{3}\right)$, contendo substrato à base de casca de pínus e vermiculita. $O$ experimento foi conduzido no delineamento inteiramente casualizado com parcelas subdivididas no tempo, sendo os fatores constituídos por seis doses de Osmocote $\AA$ (testemunha, 1000, 2000,3000, 4000 e $5000 \mathrm{mg} \mathrm{dm}^{-3}$ de substrato) e por cinco épocas de avaliação ( 0 - instante da germinação, 15, 35, 65 e 95 dias após a germinação). Foram avaliadas as seguintes características, em cada época: altura; número de folhas; número de nós; diâmetro; relação altura/diâmetro; comprimento total do sistema radicial; volume da raiz e matéria seca da raiz; caule; folha; parte aérea e total. Ao longo de 95 dias de cultivo, a fertilização testada influenciou a maioria das características de crescimento. A dose próxima a $2000 \mathrm{mg} \mathrm{dm}^{-3}$ de fertilizante correspondeu aos maiores valores médios para as características do número de folhas, diâmetro e matéria seca das mudas. A maior altura correspondeu à dose de $2743 \mathrm{mg} \mathrm{dm}^{-3}$, e a relação altura/diâmetro à dose de $3544 \mathrm{mg} \mathrm{dm}^{-3}$. Contudo, o comprimento total e o volume do sistema radicial, responderam negativamente ao sistema de adubação utilizado.
\end{abstract}

Palavras-chave: Anadenanthera colubrina; adubação; produção de mudas; Osmocote®; Mimosaceae.

\begin{abstract}
The use of controlled-release fertilizer is one among the most modern techniques utilized in seedlings production systems, on other hand there are few reports about its effects on the growth characteristics in native trees. This work aimed to test increasing doses of controlled-release fertilizer on the initial growth of Anadenanthera colubrina seedlings. The seeds were planted in small size plastic tubes $\left(110 \mathrm{~cm}^{3}\right)$, which contained Pinus bark and vermiculite as substratum base. The experiment was conducted in the whole randomized delineation in split-plot in time arrangement, where the levels were six Osmocote $\AA$ doses (control, 1000, 2000, 3000, 4000 e $5000 \mathrm{mg} \mathrm{dm}^{-3}$ ), and five evaluation times ( 0 - germination instant, 15, 35, 65 and 95 days). For each time, the growth characteristics: height; leaves number; nodes number; stem diameter; height/ diameter relation; root system total length; root volume and root, stem, leave, shoot and total dry matter were evaluated. During the 95 days, the tested fertilization influenced the majority of growth characteristics. The greater medium values of the seedlings growth characteristics: leaves number, stem diameter and dry matter; were observed in fertilizer doses around $2000 \mathrm{mg} \mathrm{dm}^{-3}$. The greater height occurred in $2743 \mathrm{mg} \mathrm{dm}^{-3}$ dose, and height/diameter relation to $3544 \mathrm{mg} \mathrm{dm}^{-3} \mathrm{dose}_{\text {. However, }}$ the characteristics root system total length and root volume presented a negative response to the fertilization system utilized.

Key-words: Anadenanthera colubrina; fertilizer application; seedlings production; Osmocote®; Mimosaceae.
\end{abstract}

\footnotetext{
1 Trabalho desenvolvido na Embrapa Florestas - CNPF, Colombo, Paraná.

${ }^{2}$ Engenheiro Florestal, Mestrando do Programa de Pós-Graduação em Engenharia Florestal, Universidade Federal do Paraná, UFPR, Bolsista CNPq. E-mail: gebrondani@yahoo.com.br.

${ }^{3}$ Bióloga, Mestranda do Programa de Pós-Graduação em Engenharia Florestal, Universidade Federal do Paraná, UFPR, Bolsista CNPq. E-mail: ariadne_bio@yahoo.com.br.

${ }^{4}$ Bióloga, Mestranda do Programa de Pós-Graduação em Engenharia Florestal, Universidade Federal do Paraná, UFPR, Bolsista CNPq. E-mail: suelen_srego@yahoo.com.br.

${ }^{5}$ Engenheira Agrônoma, Doutoranda do Programa de Pós-Graduação em Engenharia Florestal, Universidade Federal do Paraná, UFPR, Bolsista CNPq. E-mail: fergrisi@yahoo.com.br.

${ }^{6}$ Engenheiro Florestal, Doutor, Professor Associado I do Departamento de Ciências Florestais, Universidade Federal do Paraná, UFPR. E-mail: nogueira@ufpr.br.

${ }^{7}$ Engenheiro Florestal, Doutor em Silvicultura, Pesquisador da Embrapa Florestas - CNPF. Estrada da Ribeira, Km 111, Caixa Postal 319, 83411000 , Colombo (PR). E-mail: ivar@cnpf.embrapa.br. Autor para correspondência.

${ }^{8}$ Engenheira Agrônoma, Mestranda do Programa de Pós-Graduação em Ciências do Solo, Universidade Federal do Paraná, UFPR, Bolsista CNPq. E-mail: marla.agro@bol.com.br.
} 


\section{INTRODUÇÃO}

Anadenanthera colubrina (Veloso) Brenan, popularmente conhecido como angico-branco, é uma espécie arbórea pertence à família Mimosaceae, encontrada naturalmente na Floresta Estacional Semidecidual, com menor freqüência na Floresta Ombrófila Mista, Estacional Decidual, e Pantanal Mato-Grossense, e raramente no Cerradão. Esta espécie é pioneira a secundária inicial, heliófita, sendo encontrada com maior freqüência em florestas secundárias e ambientes alterados. Ocorre tanto em solos de boa disponibilidade hídrica, férteis e profundos, com textura areno-argilosa e bem drenados, como em solos rasos e de fertilidade química baixa (JUSTINIANO e FREDERICKSEN, 1998; CARVALHO, 2003).

O angico-branco é uma planta com potencial apícola e medicinal, e sua madeira pode ser utilizada na construção civil e naval, bem como para lenha e carvão. A árvore tem floração exuberante, sendo usada na arborização de estradas, parques e ruas, e é recomendada para recuperação de áreas degradadas e para reposição de mata ciliar (CARVALHO, 2003).

A fertilização do substrato é uma das fases mais importantes em um programa de produção de mudas de espécies arbóreas. Existem no mercado inúmeros tipos de fertilizantes, que variam na sua composição, forma (pó, grânulos e encapsulados) e solubilidade (VALERI e CORRADINI, 2000; MORAES NETO et al., 2003 a). Segundo SGARBI et al. (1999) a prática da adubação, além de se constituir num fator indispensável para o desenvolvimento das plantas, acelera consideravelmente o crescimento das mesmas, reduzindo os custos de produção.

No sistema de produção de mudas em tubetes, a exigência de aplicações de doses elevadas de nutrientes, visando contornar perdas por lixiviação, pode resultar em toxidez (BARROSO et al., 2000). MIKKELSEN et al. (1994) e RAUCH e MURAKAMI (1994) salientam que os fertilizantes de liberação controlada podem ter uma influência sobre o crescimento vegetal, principalmente ao reduzir a perda de nitrogênio $(\mathrm{N})$ do solo ou substrato por lixiviação. Há relatos de que a perda de $\mathrm{N}$ por lixiviação foi cerca de 20 vezes maior com a utilização de fertilizantes prontamente solúveis quando comparada ao uso de fertilizantes de liberação controlada (ENGELSJORD et al., 1997).

O maior parcelamento é uma alternativa para aumentar a eficiência da fertilização, principalmente do nitrogênio. Contudo, esta prática aumenta significativamente o custo operacional (SGARBI et al., 1999).

A utilização de fontes que apresentam uma liberação mais lenta ou controlada dos nutrientes pode reduzir gastos com mão-de-obra e energia (OLIVEIRA e SCIVITTARO, 2002). Os nutrientes encapsulados por resinas especiais, os quais são liberados através de estruturas porosas, atingem o sistema radicial das plantas mais lentamente. Essa característica pode garantir a manutenção de um sincronismo entre a liberação de nutrientes ao longo do tempo e as necessidades nutricionais, favorecendo o crescimento e desenvolvimento das plantas (DOU e ALVA, 1998; VALERI e CORRADINI, 2000; SHAVIV, 2001; SERRANO et al., 2006).

Existem vários grupos de fertilizantes de liberação lenta que são classificados nos grupos: peletizados; quimicamente alterados e recobertos. O primeiro grupo compreende os compostos de baixa solubilidade, na forma de "pellets", cuja liberação dos nutrientes depende da ação microbiana. No segundo grupo, estão incluídos os fertilizantes modificados de maneira a converter parte dos nutrientes em formas insolúveis em água, liberados ao meio de forma gradativa. Os fertilizantes recobertos, também chamados de encapsulados, incluem compostos solúveis envolvidos por uma resina permeável a água, que controla a liberação de nutrientes ao meio de cultivo. Uma vez aplicado o fertilizante encapsulado, a solução do substrato atravessa a camada de resina e dissolve os nutrientes no interior da cápsula, os quais vão sendo liberados osmoticamente para as mudas, de forma gradual (BENNETT, 1996; VALERI e CORRADINI, 2000).

Um dos principais fertilizantes de liberação lenta, utilizado comercialmente na produção de mudas, é o Osmocote $\AA$ o qual é constituído por grânulos que contêm uma combinação homogênea de nutrientes, normalmente NPK, recoberta por uma resina orgânica que regula o fornecimento de nutrientes (DOU e ALVA, 1998; VALERI e CORRADINI, 2000; OLIVEIRA e SCIVITTARO, 2002; SCIVITTARO et al., 2004), cuja liberação é diretamente proporcional à temperatura e à umidade do substrato (SGARBI et al., 1999). Como a velocidade de crescimento das mudas é diretamente proporcional ao aumento da temperatura, a liberação de nutrientes é maior nos momentos de maior exigência das mudas (VALERI e CORRADINI, 2000; OLIVEIRA e SCIVITTARO, 2002).

Dentre alguns resultados da aplicação desse fertilizante, pode-se citar o trabalho realizado por MENDONÇA et al. (2004), os quais verificaram que a dose $6,0 \mathrm{~kg} \mathrm{~m}^{-3}$ de Osmocote ${ }^{\circledR}\left(\mathrm{N}-\mathrm{P}_{2} \mathrm{O}_{5}-\mathrm{K}_{2} \mathrm{O}\right.$ 15-10-10) resultou em mudas de maracujazeiro (Passiflora edulis Sims f. flavicarpa Degener) de melhor qualidade, sendo constatado acréscimos na altura, comprimento da raiz, número de folhas e na matéria seca.

YAMANISHI et al. (2004) observaram que os tratamentos constituídos por Osmocote ${ }^{\circledR}\left(\mathrm{N}-\mathrm{P}_{2} \mathrm{O}_{5}-\right.$ $\mathrm{K}_{2} \mathrm{O}$ 14-14-14), proporcionaram bom desenvolvimento quanto à altura, diâmetro do caule, número de folhas, peso seco da parte aérea, do caule e da raiz, e aumento da área foliar de mudas de mamoeiro (Carica papaya L. Cvs. Sunrise Solo e Tainung 1), além das plantas apresentarem maiores teores de $\mathrm{N}, \mathrm{K}$ e $\mathrm{Mg}$.

Avaliando a influência de diversos substratos e duas formulações de adubo Osmocote ${ }^{\circledR}\left(\mathrm{N}-\mathrm{P}_{2} \mathrm{O}_{5}-\mathrm{K}_{2} \mathrm{O}\right.$ 14-14-14) e adubo de 
liberação normal $\left(\mathrm{N}-\mathrm{P}_{2} \mathrm{O}_{5}-\mathrm{K}_{2} \mathrm{O}\right.$ 04-14-08), no desenvolvimento de mudas de maracujazeiro-azedo (Passiflora edulis Sims f. flavicarpa Deg.), SILVA et al. (2001) observaram que o Osmocote® promoveu maior desenvolvimento das mudas. Já SGARBI et al. (1999) estudando Eucalyptus urophylla verificaram que o uso do fertilizante Osmocote $\AA$ proporcionou maior crescimento das mudas em relação à adubação convencional.

SCIVITTARO et al. (2004) constataram que, à medida que se aumentaram as quantidades das doses de fertilizante de liberação lenta, ocorreu aumento no diâmetro do caule, na produção de matéria seca da parte aérea e na acumulação de $\mathrm{N}$, $\mathrm{P}, \mathrm{K}, \mathrm{Mg}$ e B nas plantas de 'Trifoliata' (Poncirus trifoliata (L.) Raf.), sendo a melhor resposta obtida com a dose de $6000 \mathrm{mg} \mathrm{dm}^{-3}$ de substrato.

MORAES NETO et al. (2003 a), testando diversas doses e fontes de adubo em mudas de cinco espécies arbóreas, observaram que os tratamentos que utilizaram adubo de liberação controlada $\left(\mathrm{N}-\mathrm{P}_{2} \mathrm{O}_{5}-\mathrm{K}_{2} \mathrm{O}\right.$ 19-06-10) nas doses de
$3200 \mathrm{mg} \mathrm{dm}^{-3}$ e $4800 \mathrm{mg} \mathrm{dm}^{-3}$ de substrato, resultaram em mudas de boa qualidade quanto a altura, diâmetro do colo, matéria seca da parte aérea, da raiz e do total por muda para todas as espécies estudadas por estes autores.

O presente trabalho teve como objetivo testar doses crescentes de fertilizante de liberação controlada no crescimento inicial de mudas de Anadenanthera colubrina (Veloso) Brenan cultivadas em tubetes.

\section{MATERIAL E MÉTODOS}

$O$ experimento foi conduzido em casa de vegetação de vidro, pertencente ao Laboratório de Propagação de Plantas da Embrapa Florestas CNPF, situada em Colombo - PR, no período de abril a agosto de 2007, localizada nas coordenadas $25^{\circ}$ $20^{\prime} \mathrm{S}$ e 49 14' W a uma altitude média de $950 \mathrm{~m}$, clima Cfb segundo classificação de Köppen. Os dados de temperatura registrados no interior da casa de vegetação, durante o período experimental, encontram-se na Tabela 1.

TABELA 1 - Médias mensais das temperaturas máxima, média e mínima do ar registradas em casa de vegetação de vidro no período de crescimento inicial de mudas de Anadenanthera colubrina.

\begin{tabular}{cccc}
\hline & \multicolumn{3}{c}{ Temperatura do Ar } \\
\cline { 2 - 3 } Mês de 2007 & Máxima & Média & Mínima \\
\cline { 2 - 4 } & & ${ }^{\circ} \mathrm{C} \pm \mathrm{s}$ & $16,6 \pm 2,97$ \\
Abril & $28,9 \pm 3,98$ & $22,8 \pm 3,02$ & $11,2 \pm 4,87$ \\
Maio & $24,2 \pm 3,75$ & $17,7 \pm 3,63$ & $10,5 \pm 3,35$ \\
Junho & $28,3 \pm 3,13$ & $19,4 \pm 2,26$ & $8,9 \pm 4,41$ \\
Julho & $25,4 \pm 4,74$ & $17,2 \pm 3,51$ & $10,9 \pm 2,50$ \\
Agosto & $28,7 \pm 3,28$ & $19,8 \pm 2,31$ & \\
\hline
\end{tabular}

s - desvio padrão em relação ao valor médio. Fonte: Laboratório de Propagação de Plantas - Embrapa Florestas.

As mudas de angico-branco foram obtidas por meio de sementes coletadas na região de Tunas - PR no ano de 2006. Após o processo de seleção e padronização do tamanho das sementes (em torno de $1 \mathrm{~cm} \times 0,8 \mathrm{~cm})$, com a remoção das atacadas por insetos e mal formadas, estas foram semeadas na profundidade de $0,5 \mathrm{~cm}$, diretamente em tubetes plásticos de formato cônico com capacidade de 110 $\mathrm{cm}^{3}$, contendo substrato comercial a base de casca de pínus e vermiculita (Plantmax Florestal®).

O experimento foi conduzido no delineamento inteiramente casualizado com parcelas subdivididas no tempo (STEEL e TORRIE, 1980), sendo o fator fertilização, constituído por seis doses de Osmocote® $\left(\mathrm{N}-\mathrm{P}_{2} \mathrm{O}_{5}-\mathrm{K}_{2} \mathrm{O}\right.$ 14-14-14) (T1 testemunha - substrato sem adição de Osmocote®; T2 - 1000; T3 - 2000; T4 - 3000; T5 - 4000; e T6 $5000 \mathrm{mg} \mathrm{dm}^{-3}$, respectivamente) com período total de liberação entre 90 e 120 dias. O outro fator foi constituído por cinco épocas de avaliação (0 instante da germinação, 15, 35, 65 e 95 dias após a germinação). O fertilizante foi incorporado e homogeneizado junto ao substrato antes de ser efetuada a semeadura. $O$ experimento contou com cinco repetições, totalizando 25 mudas para a composição de cada repetição.

Os tubetes contendo as mudas foram dispostos seqüencialmente em grades metálicas, deixando-se uma célula entre um tubete e outro. Diariamente foram realizadas regas manuais com água, evitando o seu excesso a fim de minimizar perdas de nutrientes por lixiviação. As mudas que morreram não foram repostas.

Em cada avaliação foram amostradas 3 plantas por repetição, das quais foram coletados dados referentes à altura (do colo até a inserção da gema apical), número de folhas, número de nós, diâmetro (1 cm acima do colo), relação altura/ diâmetro, comprimento total do sistema radicial, volume da raiz e matéria seca da raiz, do caule, da folha, da parte aérea e do total. Os indivíduos amostrados foram descartados, caracterizando amostragem destrutiva.

A altura e diâmetro das mudas foram mensurados com o uso de uma régua graduada e paquímetro digital $(0,01 \mathrm{~mm})$, respectivamente. Para a determinação da matéria seca, as amostras da raiz, do caule, da folha, da parte aérea e do total foram lavadas com água deionizada e dispostas em 
BRONDANI, G.E. et al. Fertilização de liberação controlada...

sacos de papel para a secagem em estufa a $60{ }^{\circ} \mathrm{C}$, até apresentarem massa constante. Em seguida, procedeu-se a pesagem das amostras com a utilização de balança analítica $(0,001 \mathrm{~g})$. A dose de máxima eficiência técnica (DMET) referente a cada característica amostrada foi determinada a partir do cálculo das derivadas parciais das equações ajustadas pela análise de regressão.

O comprimento total do sistema radicial e o volume de raízes foram determinados por meio do aparelho WinRHIZO pertencente ao Laboratório de Fitotecnia do Setor de Ciências Agrárias da Universidade Federal do Paraná, que utiliza como princípio de mensuração o método proposto por TENNANT (1975).
Os dados foram submetidos ao teste de Bartlett e, em seguida à análise de variância (ANOVA) e regressão polinomial, a $5 \%$ de probabilidade de erro, utilizando o pacote estatístico SOC (EMBRAPA, 1990).

\section{RESULTADOS E DISCUSSÃO}

A altura das mudas de angico-branco variou aos 95 dias em função das doses de fertilizante de liberação controlada, apresentando comportamento quadrático. A dose de máxima eficiência técnica (DMET) foi estimada em $2743 \mathrm{mg} \mathrm{dm}^{-3}$ de fertilizante, correspondendo a uma altura de $17,2 \mathrm{~cm}$ e a um acréscimo de aproximadamente $16 \%$ em relação à testemunha (substrato sem adição de Osmocote ${ }^{\circledR}$ ) (Figura 1 a).

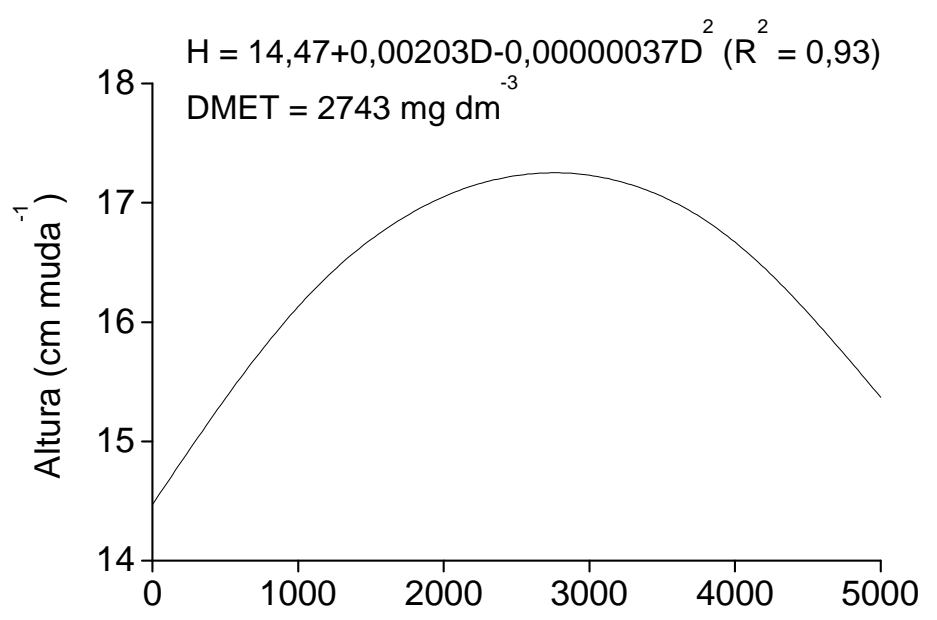

(a)

Dose de Osmocote (mg dm ${ }^{-3}$ )

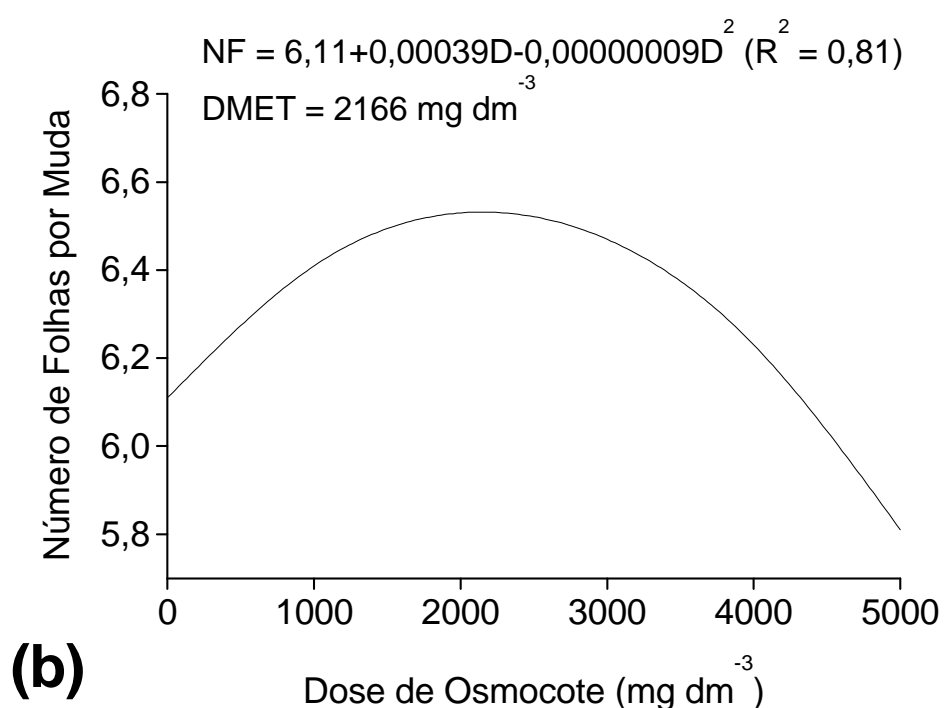

FIGURA 1 - (a): Altura das mudas (H) e, (b): número de folhas por muda (NF) de Anadenanthera colubrina, aos 95 dias após a germinação em função das doses de fertilizante de liberação lenta. 
Resposta semelhante foi constatada quanto ao número de folhas por muda, aos 95 dias após a germinação, que também apresentou efeito quadrático em função das doses de fertilizante. A DMET foi estimada em $2166 \mathrm{mg} \mathrm{dm}^{-3}$ de fertilizante, resultando em 6,5 folhas por muda. Na dose de 5000 $\mathrm{mg} \mathrm{dm} \mathrm{dm}^{-3}$ ocorreu efeito negativo, tanto para altura como para o número de folhas por muda (Figura 1 b), sendo também constatado, por análise visual, princípio de clorose em algumas folhas, o que talvez indique sintomas de toxidez. O número de nós por muda não variou em função da dose de fertilizante, apresentando valor médio de 6,9 nós por muda, aos 95 dias após a germinação, independente da data de avaliação.

Embora em outras condições de trabalho, MORAES NETO et al. (2003 b) também evidenciaram resposta similar no incremento em altura com aplicação de Osmocote $\AA$ na produção de mudas de Guazuma ulmifolia, Peltophorum dubium, Eucalyptus grandis, Calycophyllum spruceanum e Pinus caribaea var. caribaea, porém com amplitudes diferentes. Para essas espécies, cultivadas em tubetes de $50 \mathrm{~cm}^{3}$, as doses compreendidas entre 4280 e $6420 \mathrm{mg} \mathrm{dm}^{-3}$ de Osmocote® apresentaram os maiores valores em altura, aos 125 dias.

Em outro estudo, MORAES NETO et al. (2003 a) ao comparar diferentes doses de adubação de liberação controlada com a convencional e, adubação de liberação controlada mais adubação periódica e de cobertura, verificaram que as espécies Guazuma ulmifolia, Croton floribundus e Gallesia integrifolia apresentaram maior crescimento em altura nas doses de 3200 e $4800 \mathrm{mg} \mathrm{dm}^{-3}$ de adubo de liberação controlada. Os efeitos obtidos para Myroxylon peruiferum e Peltophorum dubium, em função da adubação convencional e dos tratamentos com adição de adubação periódica, foram inferiores a fertilização de liberação lenta nas doses de 4800 , 3200 e $4800 \mathrm{mg} \mathrm{dm}^{-3}$, respectivamente.

SERRANO et al. (2006) observaram resposta linear crescente para as características da altura, área foliar, diâmetro e número de folhas, na produção de porta-enxerto cítrico limoeiro "cravo" (Citrus limonia) ao testar diferentes doses de fertilizante de liberação controlada $(1320,2640$, 3960,5280 e $6600 \mathrm{mg} \mathrm{dm}^{-3}$ de Osmocote $\AA$ ), cultivados em tubetes, contendo substrato a base de casca de pínus e vermiculita.

Houve interação entre as doses de fertilizante e épocas de avaliação para as características do diâmetro e relação altura/diâmetro das mudas (Figura 2 a). A estimativa da dose de $1513 \mathrm{mg} \mathrm{dm}^{-3}$ de fertilizante, aproximadamente aos 92 dias após a germinação, correspondeu ao maior diâmetro (DI) apresentado pelas mudas, com 2,12 $\mathrm{mm}$, correspondendo acréscimo de $1 \%$ ao comparar com a testemunha. Além disso, se verifica decréscimo para essa variável aos 95 dias, apresentando $2 \mathrm{~mm}$ na dose de $5000 \mathrm{mg} \mathrm{dm}^{-3}$ de fertilizante. Esse efeito correspondeu em redução de aproximadamente $5 \%$ em relação ao valor apresentado pela testemunha.
MORAES NETO et al. (2003 b) observaram que o diâmetro de Guazuma ulmifolia, Peltophorum dubium e Calycophyllum spruceanum não apresentou variação em função da adubação com Osmocote $\AA$. No entanto, MORAES NETO et al. (2003 a) perceberam que para Guazuma ulmifolia os melhores tratamentos para o crescimento em diâmetro foram os de adubação de liberação lenta nas doses 3200 e $4800 \mathrm{mg} \mathrm{dm}^{-3}$, enquanto que as espécies Croton floribundus, Peltophorum dubium e Gallesia integrifolia não apresentaram ganhos significativos para essas doses.

Constatou-se que, aos 71 dias, a dose de $3544 \mathrm{mg} \mathrm{dm}^{-3}$ de fertilizante promoveu o máximo valor para a relação altura/diâmetro (HDI) das mudas, resultando em HDI de $8,4 \mathrm{~cm} \mathrm{~mm}^{-1}$ (Figura $2 \mathrm{~b}$ ). A partir dessa época de avaliação as mudas de angico-branco cresceram mais em diâmetro do que em altura, e a relação altura/diâmetro começou a decrescer. Aos 95 dias, os valores de HDI ficaram compreendidos entre $7,1 \mathrm{~cm} \mathrm{~mm}^{-1}$ (testemunha) a $7,6 \mathrm{~cm} \mathrm{~mm}^{-1}$ (4000 $\mathrm{mg} \mathrm{dm}^{-3}$ de fertilizante).

A matéria seca do caule (MSC), das folhas (MSF), da parte aérea (MSPA) e do total (MST) também apresentaram comportamento quadrático em função das doses de fertilizante, aos 95 dias após a germinação (Figura 3). Os valores da DMET para a MSC, MSF, MSPA e MST foram estimados em 2261, 1786, 1900 e $1539 \mathrm{mg} \mathrm{dm}^{-3}$ de fertilizante, as quais promoveram os maiores incrementos para essas características.

Comportamento linear decrescente foi observado apenas para a matéria seca da raiz (MSR), com uma redução de aproximadamente $30 \%$ em relação à testemunha na dose de 5000 mg dm ${ }^{3}$ de fertilizante (Figura 3 ).

SERRANO et al. (2006), observaram resposta linear crescente para as características de matéria seca da parte aérea e radicial em limoeiro "cravo" (Citrus limonia), em função da adubação de Osmocote ${ }^{\circledR}$. MORAES NETO et al. (2003 b) verificaram que a biomassa total da espécie Calycophyllum spruceanum aumentou com as doses de 4280 e $6420 \mathrm{mg} \mathrm{dm}^{-3}$ de Osmocote ${ }^{\circledR}$. Para Eucalyptus urophylla, SGARBI et al. (1999), verificaram que aos 90 dias após o plantio das mudas, a maior produção de matéria seca da parte aérea e do sistema radicial foi obtida, respectivamente, com as doses de 3300 e $2700 \mathrm{mg}$ $\mathrm{dm}^{-3}$.

O incremento da matéria seca em função da fertilização utilizada parece estar ligado, dentre outros fatores, com a espécie em estudo. MORAES NETO et al. (2003 a) observaram que em Guazuma ulmifolia, os tratamentos de adubação convencional e adição de adubação periódica e de cobertura não proporcionaram maiores valores de biomassa seca total que o tratamento de liberação controlada nas doses de 3200 e $4800 \mathrm{mg} \mathrm{dm}^{-3}$. Entretanto, as doses de adubação de liberação controlada de 3200 e 4800 $\mathrm{mg} \mathrm{dm}^{-3}$ para Peltophorum dubium, $3200 \mathrm{mg} \mathrm{dm}^{-3}$ para Gallesia integrifolia e 1600, 3200 e $4800 \mathrm{mg}$ $\mathrm{dm}^{-3}$ para Myroxylon peruiferum, apresentaram as melhores produções de biomassa seca total. 
BRONDANI, G.E. et al. Fertilização de liberação controlada...
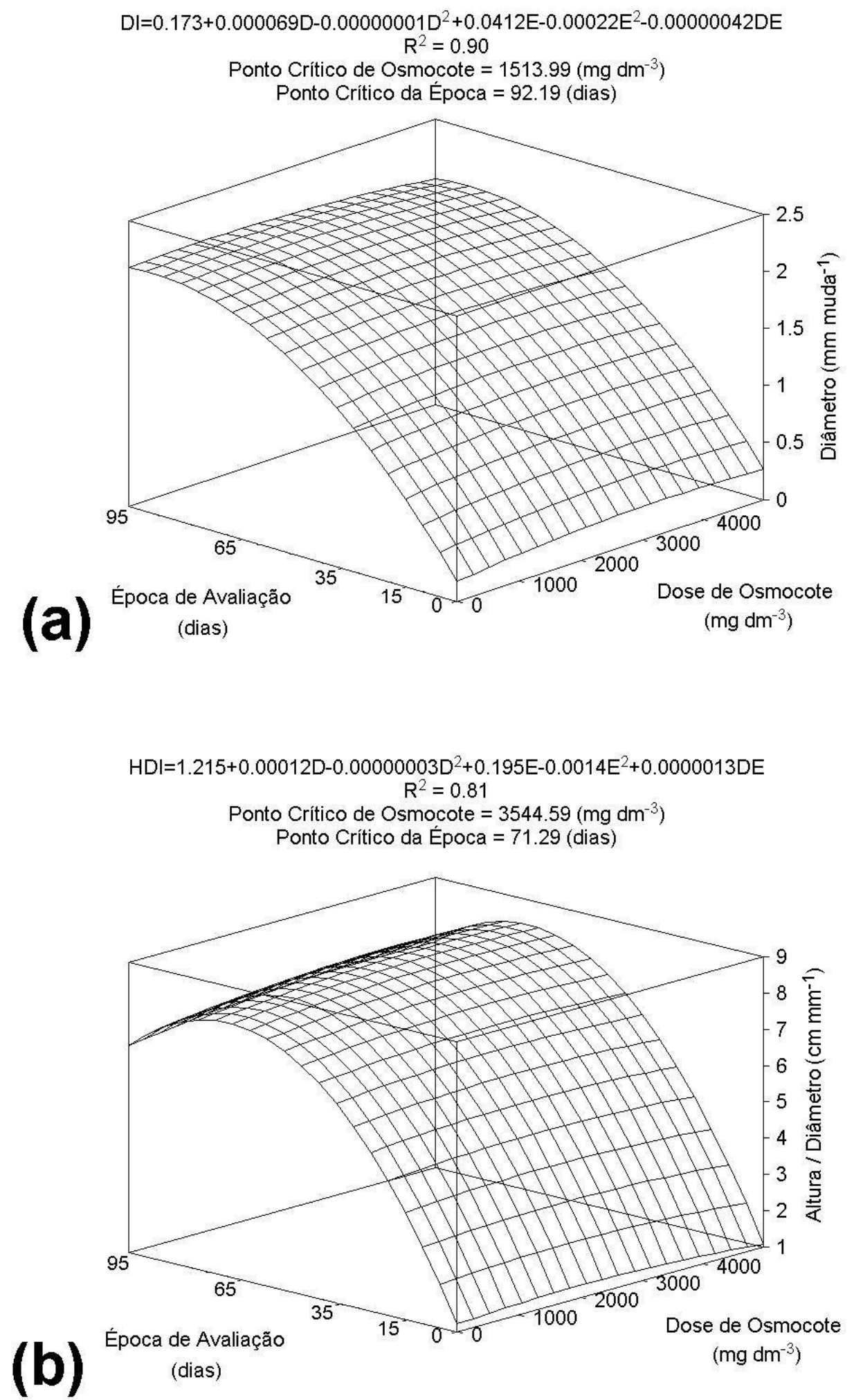

FIGURA 2 - (a): diâmetro por muda (DI) e, (b): relação altura/diâmetro (HDI) de Anadenanthera colubrina em função das doses de fertilizante (D) e das épocas de avaliação (E). 

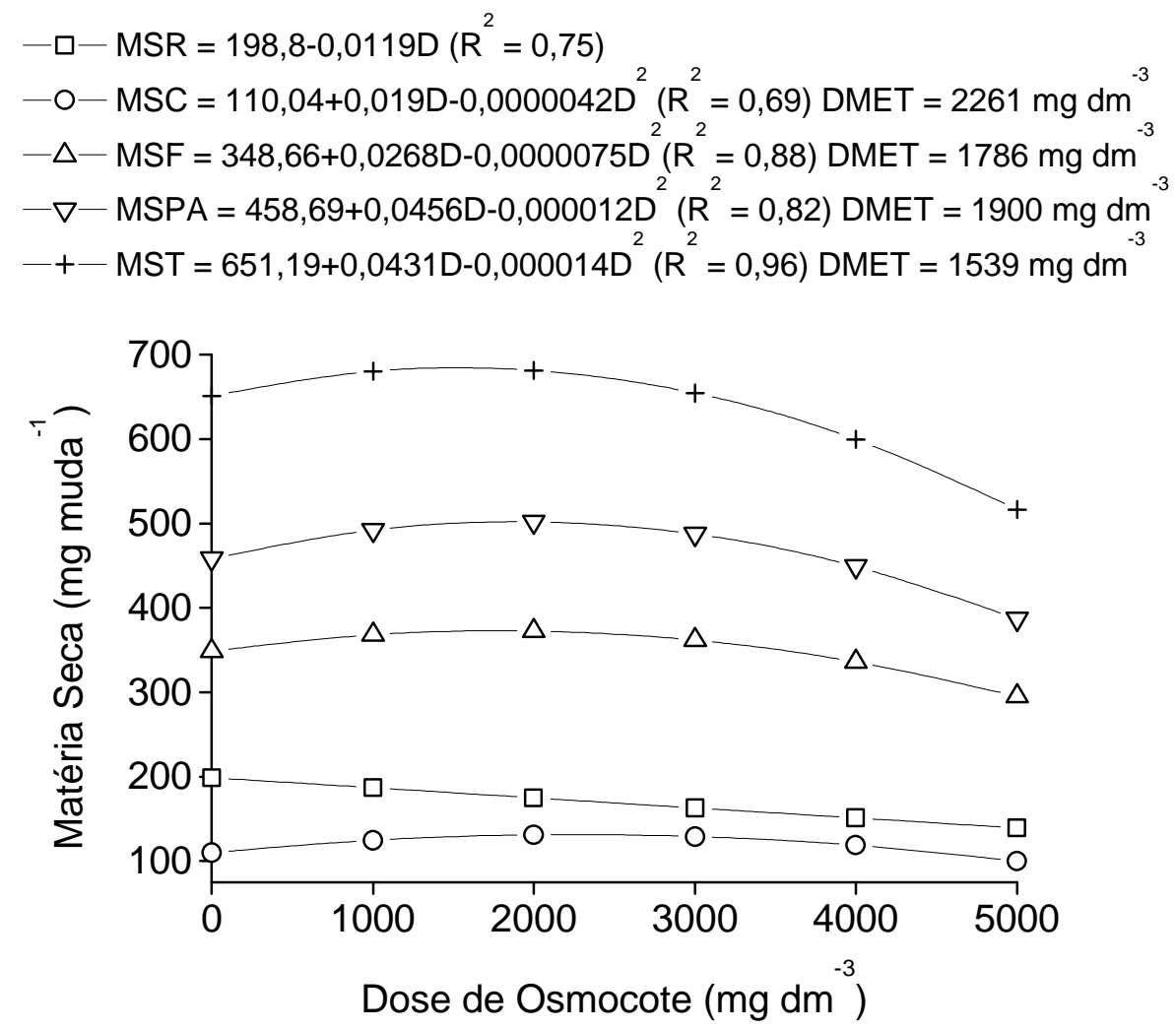

FIGURA 3 - Matéria seca da raiz (MSR), caule (MSC), folha (MSF), parte aérea (MSPA) e total (MST) de mudas de Anadenanthera colubrina, aos 95 dias após a germinação em função das doses de fertilizante.

DOU e ALVA (1998), estudando o crescimento de porta-enxerto de citrus em função da aplicação de nitrogênio (N) a $400 \mathrm{mg} \mathrm{kg}^{-1}$ de solo, tendo Osmocote® (270 dias de liberação total de nutrientes a $25 \stackrel{\circ}{\circ}$ ) como uma das fontes de fertilizante testada, observaram diferenças entre as variedades citrumelo "Swingle" (Citrus paradisi $\mathrm{x}$ Poncirus trifoliata) e cleópatra mandarin (Citrus reticulata) que apresentaram valores médios de matéria seca: de $2,1 \mathrm{~g}$ e $4,4 \mathrm{~g}$ para a folha; $3,0 \mathrm{~g}$ e $6,7 \mathrm{~g}$ para o caule; $2,7 \mathrm{~g}$ e $3,7 \mathrm{~g}$ para a raiz; e $8,0 \mathrm{~g} \mathrm{e}$ $14,8 \mathrm{~g}$ por planta, respectivamente.

A interação entre as épocas de avaliação e doses de fertilizante foi significativa para as características de comprimento total do sistema radicial (CTSR) e volume radicial (V) (Figura 4). Tanto o CTSR quanto o $\mathrm{V}$ responderam negativamente ao aumento da dose de fertilizante. Com o passar do tempo, o efeito negativo das maiores doses de fertilizante foi se tornando mais pronunciado para ambas as características. Ao final de 95 dias após a germinação, estimou-se redução com a dose de $5000 \mathrm{mg} \mathrm{dm}^{-3}$ de aproximadamente $51 \%$ e $42 \%$, respectivamente para o CTSR e o V, em comparação com a testemunha.

Os fatores nutricionais influenciam o crescimento e a morfologia de órgãos particulares das plantas de maneira específica. Como as raízes são os órgãos de maior contato direto com o ambiente nutricional da planta, elas são especialmente propensas a serem afetadas por esse ambiente (EPSTEIN e BLOOM, 2004).

Esse efeito pode ser constatado na Figura 5 a, na qual se observa que aos 35 dias após a germinação, as raízes das plântulas de angicobranco já evidenciavam alterações morfológicas com o aumento das doses de Osmocote $\AA$. Aos 95 dias, o tratamento com $5000 \mathrm{mg} \mathrm{dm}^{-3}$ de Osmocote $\AA$ apresentou maiores alterações na formação radicial (Figura 5 b).

\section{CONCLUSÕES}

1) As doses de adubo de liberação lenta influenciaram o crescimento inicial das mudas de angico-branco, quando cultivadas em sistema de tubetes $\left(110 \mathrm{~cm}^{3}\right)$, contendo substrato a base de casa de pínus e vermiculita.

2) A dose próxima a $2000 \mathrm{mg} \mathrm{dm}^{-3} \mathrm{de}$ fertilizante apresentou os melhores valores para as características número de folhas, diâmetro e matéria seca das mudas, nas condições estudadas.

3) A maior altura correspondeu a dose de $2743 \mathrm{mg} \mathrm{dm}^{-3} \mathrm{e}$ a maior relação altura/diâmetro à $3544 \mathrm{mg} \mathrm{dm}^{-3}$.

4) As características comprimento total do sistema radicial e volume radicial responderam negativamente em função da fertilização, ao longo de 95 dias de cultivo.

\section{AGRADECIMENTOS}

À Universidade Federal do Paraná (UFPR) e à Embrapa Florestas - CNPF pelo apoio concedido. 
BRONDANI, G.E. et al. Fertilização de liberação controlada...

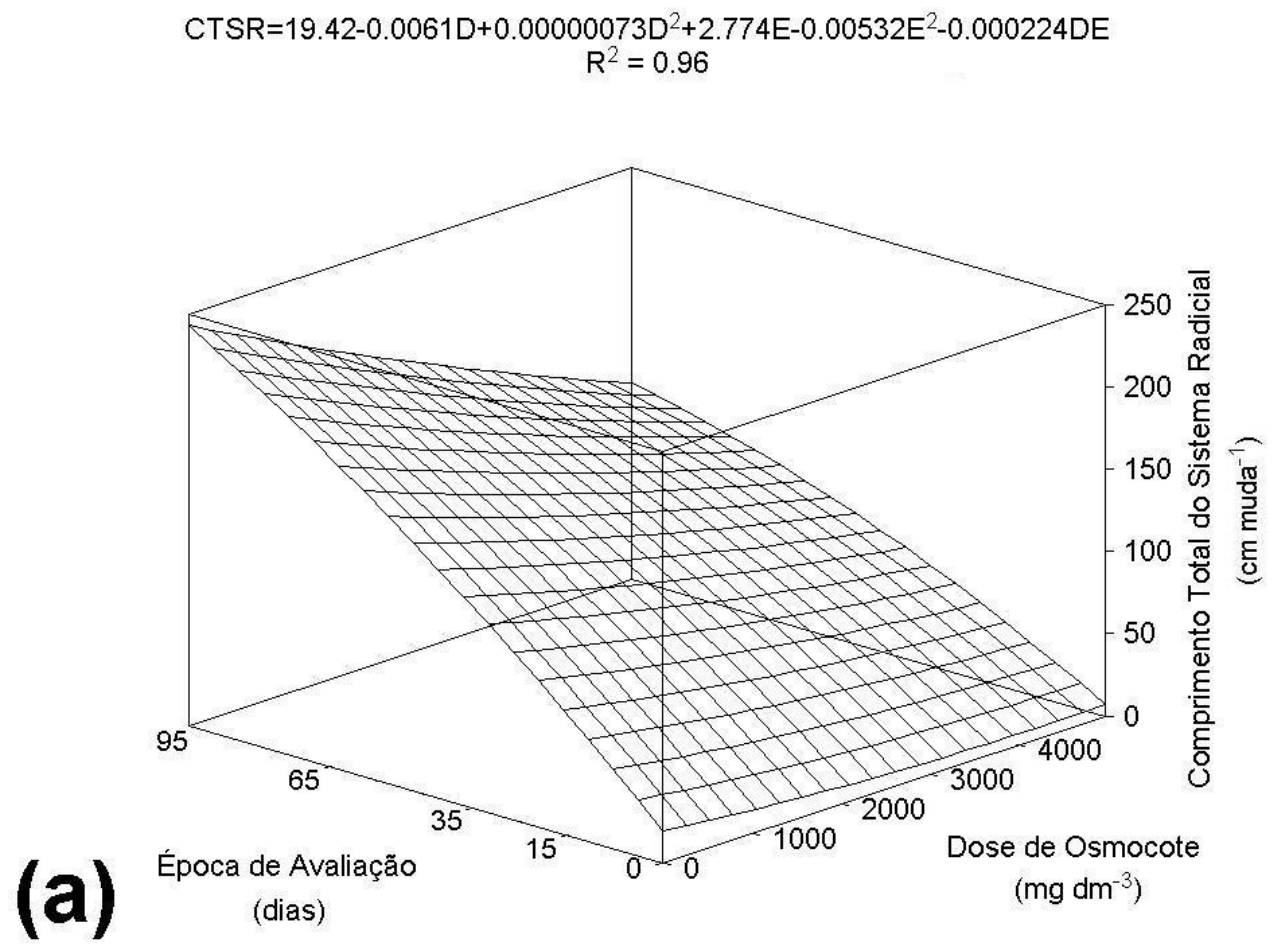
$V=0.02+0.000011 D+0.0108 E+0.0000114 E^{2}-0.00000114 D E$
$R^{2}=0.96$

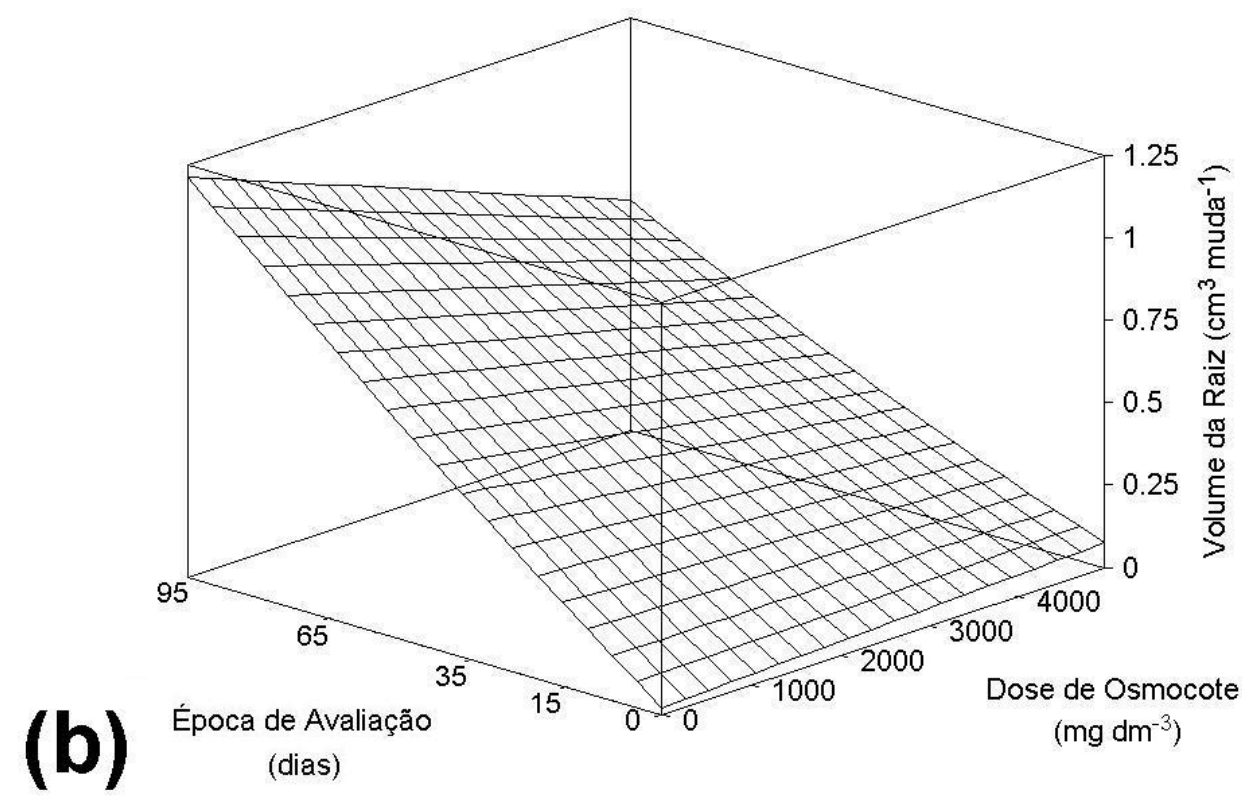

FIGURA 4 - (a): comprimento total do sistema radicial (CTSR) e, (b): volume da raiz (V) de mudas de Anadenanthera colubrina em função das doses de fertilizante (D) e das épocas de avaliação (E). 

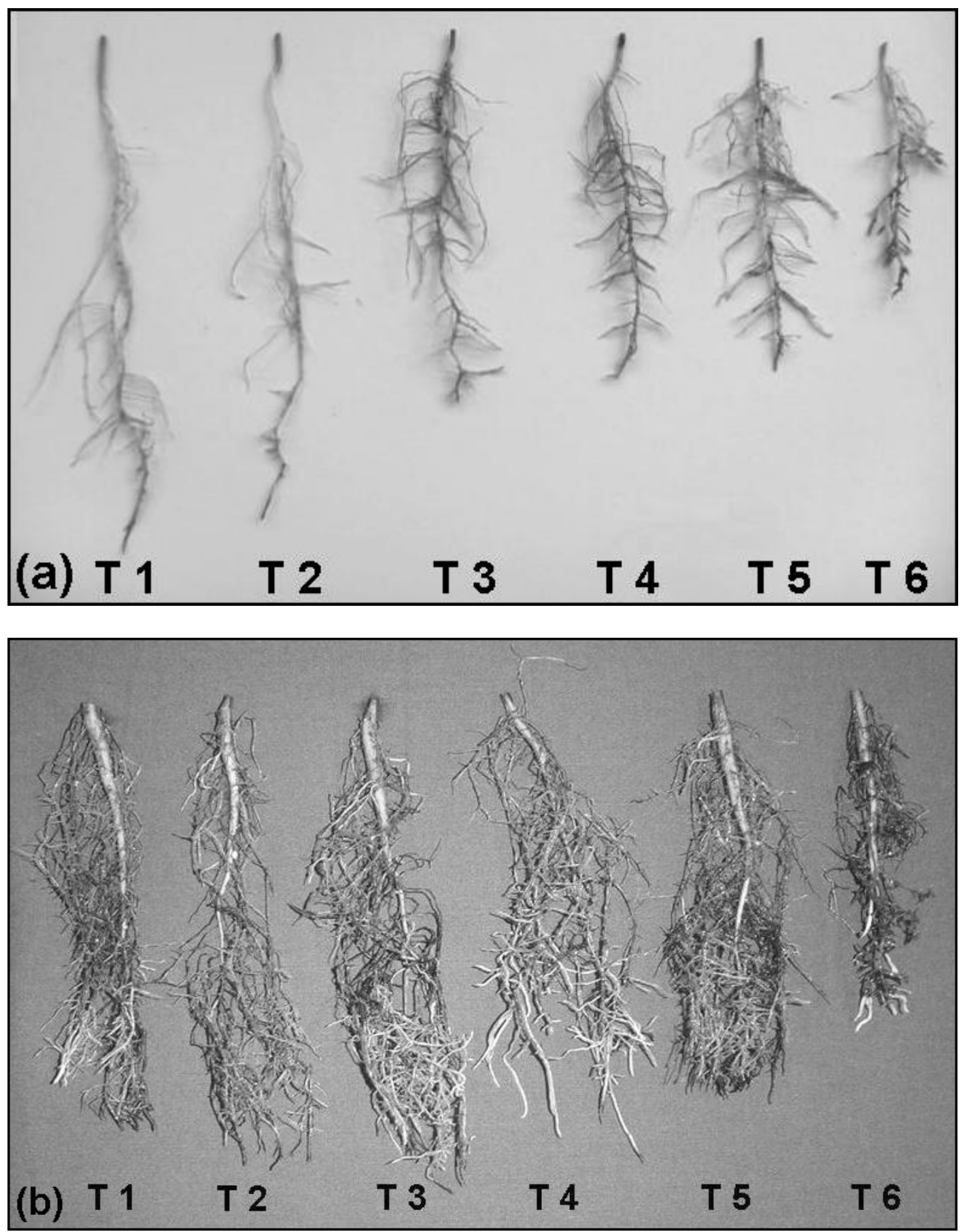

FIGURA 5 - (a): detalhe das raízes aos 35 dias e, (b): aos 95 dias após a germinação de mudas de Anadenanthera colubrina em função das concentrações de fertilizante. T1 - testemunha (substrato sem adição de Osmocote $\AA$ ), T2 - 1000, T3 - 2000, T4 - 3000, T5 - 4000 e T6 - 5000 mg dm de $^{-3}$ Osmocoteß. 


\section{REFERÊNCIAS}

1. BARROSO, D.G.; CARNEIRO, J.G.A.; LELES, P.S.S. Qualidade de mudas de Eucalyptus camaldulensis e E. urophylla produzidas em tubetes e em blocos prensados, com diferentes substratos. Floresta e Ambiente, v. 7, n. 1, p. 238250,2000

2. BENNETT, E. Slow-release fertilizers. Virginia Gardener Newsletter, v. 11, n. 4, 1996. Disponível em: <http:// www.ext.vt.edu/departments/envirohort/articles/misc/slowrels.html>. Acesso em 20 out 2007.

3. CARVALHO, P.E.R. Espécies arbóreas brasileiras. Colombo: Embrapa Florestas, 2003. v. 1. 1039 p.

4. DOU, H.; ALVA, A.K. Nitrogen uptake and growth of two citrus rootstock seedlings in a sandy soil receiving different controlled-release fertilizer sources. Biology and Fertility of Soils, v. 26, n. 3, p. 169-172, 1998.

5. EMBRAPA. Núcleo Tecnológico para Informática. SOC - Software Científico. Campinas, 1990.

6. ENGELSJORD, M.E.; FOSTAD, O.; SINGH, B.R. Effects of temperature on nutrient release from slow-release fertilizers. Nutrient Cycling in Agroecosystems, v. 46, p. 179-187, 1997.

7. EPSTEIN, E.; BLOOM, A. Nutrição mineral de plantas: princípios e perspectivas. 2. ed. Trad. NUNES, M. E. T. Londrina: Editora Planta, 2004. 403 p.

8. JUSTINIANO, M.J.; FREDERICKSEN, T.S. Ecologia y silvicultura de especies menos conocidas: curupaú Anadenanthera colubrina (Vell. Conc.) Benth. Mimosoideae. Santa Cruz: BOLFOR, 1998. 31 p.

9. MENDONÇA, V.; RAMOS, J.D.; GONTIJO, T.C.A.; MARTINS, P.C.C.; JESUS DANTAS, D.J.D.; PIO, R.; ABREU, N.A.A. Osmocote $\AA$ e substratos alternativos na produção de mudas de maracujazeiro-amarelo. Ciência e Agrotecnologia, v. 28 , n. 4, p. 799-806, 2004.

10. MIKKELSEN, R.L.; WILLIAMS, H.M.; BEHEL Jr., A.D. Nitrogen leaching and plant uptake from controlled-release fertilizers. Fertilizer Research, v. 37, p. 43-50, 1994.

11. MORAES NETO, S.P.; GONÇALVES, J.L.M.; RODRIGUES, C.J.; GERES, W.L.A.; DUCATTI, F.; AGUIRRE Jr., J.H. Produção de mudas de espécies arbóreas nativas com combinações de adubos de liberação controlada e prontamente solúveis. Revista Árvore, v. 27, n. 6, p. 779-789, 2003 a

12. MORAES NETO, S.P.; GONÇALVES, J.L.M.; ARTHUR Jr., J.C.; DUCATTI, F.; AGUIRRE Jr., J.H. Fertilização de mudas de espécies arbóreas nativas e exóticas. Revista Árvore, v. 27, n. 2, p. 129-137, 2003 b.

13. OLIVEIRA, R.P.; SCIVITTARO, W.B. Comparação de custos de sistemas de adubação para mudas de citros: fontes liberação lenta x solúveis. Pelotas: Embrapa Clima Temperado, 2002. 4 p. (Comunicado Técnico, 74).

14. RAUCH, F.D.; MURAKAMI, P.K. Comparison between two controlled-release fertilizers on selected foliage plants in an artificial potting mix. Fertilizer Research, v. 39, p. 89-95, 1994.

15. SCIVITTARO, W.B.; OLIVEIRA, R.P.; RADMANN, E.B. Doses de fertilizante de liberação lenta na formação do portaenxerto 'trifoliata'. Revista Brasileira de Fruticultura, v. 26, n. 3, p. 520-523, 2004.

16. SERRANO, L.A.L.; MARINHO, C.S.; BARROSO, D.G.; CARVALHO, A.J.C. Sistema de blocos prensados e doses de adubo de liberação lenta na formação de porta-enxerto cítrico. Ciência Rural, v. 36, n. 2, p. 441-447, 2006.

17. SGARBI, F.; SILVEIRA, R.L.V.A.; HIGASHI, E.N.; ANDRADE E PAULA, T.; MOREIRA, A.; RIBEIRO, F.A. Influência da aplicação de fertilizante de liberação controlada na produção de mudas de um clone de Eucalyptus urophylla. In: SIMPÓSIO SOBRE FERTILIZAÇÃO E NUTRIÇÃO FLORESTAL, 2., 1999, Piracicaba. Anais. Piracicaba: IPEF, ESALQ, 1999. p. $120-125$

18. SHAVIV, A. Advances in controlled-release fertilizers. Advances in Agronomy, v. 71, p.1-49, 2001.

19. SILVA, R.P.; PEIXOTO, J.R.; JUNQUEIRA, N.T.V. Influência de diversos substratos no desenvolvimento de mudas de maracujazeiro azedo (Passiflora edulis Sims f. flavicarpa Deg). Revista Brasileira de Fruticultura, v. 23, n. 2, p. 377-381, 2001.

20. STEEL, R.G.D.; TORRIE, J.H. Principles and procedures of statistics. 2. ed. New York: McGraw-Hill, 1980. 633 p.

21. TENNANT, D. A test of a modified line intersect method of estimating root length. The Journal of Ecology, v. 63, n. 3, p. 995-1001, 1975.

22. VALERI, S.V.; CORRADINI, L. Fertilização em viveiros para produção de mudas de Eucalyptus e Pinus. In: GONÇALVES, L. M.; BENEDETTI, V. (Eds.). Nutrição e fertilização florestal. Piracicaba: IPEF, 2000. p. 167-190.

23. YAMANISHI, O.K.; FAGUNDES, G.R.; MACHADO FILHO, J.A.; VALONE, G.V. Efeito de diferentes substratos e duas formas de adubação na produção de mudas de mamoeiro. Revista Brasileira de Fruticultura, v. 26, n. 2, p. 276279, 2004. 